\title{
APPLICATION OF STATISTIC EXPERIMENTAL DESIGN TO ASSESS THE EFFECT OF GAMMA- IRRADIATION PRE-TREATMENT ON THE DRYING CHARACTERISTICS AND QUALITIES OF WHEAT
}

Yong $\mathrm{Yu}^{1, *}$, Jun Wang ${ }^{1}$

${ }^{I}$ Department of Biosystems Engineering, Zhejiang University, Hangzhou, 31002

* Corresponding author, Address: Department of Biosystems Engineering, Zhejiang University, Hangzhou, 31002, Zhejiang Province, P. R. China, Tel: +86-571-86971053, Email:yyu_zju@yahoo.com.cn

Abstract: Wheat, pretreated by 60Co gamma irradiation, was dried by hot-air with irradiation dosage 0-3 kGy, drying temperature $40-60{ }^{\circ} \mathrm{C}$, and initial moisture contents $19-25 \%$ (drying basis). The drying characteristics and dried qualities of wheat were evaluated based on drying time, average dehydration rate, wet gluten content (WGC), moisture content of wet gluten (MCWG)and titratable acidity (TA). A quadratic rotation-orthogonal composite experimental design, with three variables (at five levels) and five response functions, and analysis method were employed to study the effect of three variables on the individual response functions. The five response functions (drying time, average dehydration rate, WGC, MCWG, TA) correlated with these variables by second order polynomials consisting of linear, quadratic and interaction terms. A high correlation coefficient indicated the suitability of the second order polynomial to predict these response functions. The linear, interaction and quadratic effects of three variables on the five response functions were all studied.

Keywords: $\quad$ statistic experimental design, gamma irradiation, drying, quality, wheat

Please use the following format when citing this chapter:

Yu, Y. and Wang, J., 2009, in IFIP International Federation for Information Processing, Volume 294, Computer and Computing Technologies in Agriculture II, Volume 2, eds. D. Li, Z. Chunjiang, (Boston: Springer), pp. 817-829. 


\section{INTRODUCTION}

wheat was one of the major cereals and harvested usually at high moisture content to minimize shattering losses. Moisture content was one of the most important factors affecting the quality of wheat during storage and subsequent handling. The moisture content of wheat at harvesting was as high as $20-35 \%$ (drying basis). Drying was necessary to prevent quality during storage. The current drying method used widely was hot-air drying. The drawback of this method was a long drying time and the controlling of drying conditions (e.g. increasing drying temperature) will result in the quality of dried wheat. It is necessary that a new method be applied for not only high dehydration rate but also quality of wheat.

Technology of gamma irradiation had long been employed to decontaminate and to extend the shelf life of food. 1-3 kGy dose was efficient for bacterial decontamination and elimination of potential pathogens and improve the keeping quality of fruit, vegetable (Bidawid, et al., 2000), condiment (Kamat, et al., 2003), and beef (Formanek, et al., 2003); a low dose of 50 Gy and 150 Gy could completely prevent and control the apple maggot (Hallman, 2004) and Hawaii's fruit flies (Follett, 2004), etc.

Irradiation, as a pre-treatment method before drying, was studied about its influence on the drying characteristics of apple and potato slices (Wang, et al., 2002). The interior tissue structure of apple would be changed and injured by ${ }^{60} \mathrm{Co}$ gamma ray irradiation, which would bring about different drying characteristics and affect dehydration rate and qualities of dried products. L-value, Vc content, and rehydration ratio of dried samples were greatly affected by irradiation dose (Wang, et al., 2003). Dehydration rate was increased and Vc content was decreased with increasing dose, and Lvalues of dried product after irradiation was greater than under nonirradiation.

The qualities would change after dried rough rice and wheat was irradiated (Wu, et al., 2002). Apparent amylose content (ACC) was reduced and gel consistency (GC) was improved with increasing dose (0-12 kGy). Four major parameters of RVA profile, peak viscosity, hot pasting viscosity, cool pasting viscosity, and setback viscosity, were considerably decreased with increasing dose. The viscosity of rice irradiated were reduced by $25 \%$, $50 \%, 65 \%, 72 \%$ and $74 \%$ for Local Black barley cultivar, while, in Shoaa cultivar the reductions were $15 \%, 30 \%, 52 \%, 69 \%$ and $67 \%$ at $10,50,100$, 150 and $200 \mathrm{kGy}$, respectively (Al-Kaisey, et al., 2002).

It can be found that, irradiation, as a pre-treatment method, can increase dehydration rate of apple and potato and change the qualities of wheat that was irradiated after drying. It was necessary to studies the effect of gamma radiation on drying characteristics and quality of wheat that was irradiated before drying, and to find a new wheat drying method. The previous researches showed that the drying time, average dehydration rate, WGC, 
MCWG and TA of wheat were signifcant effected by gamma irradiation (Yu et al., 2005; 2006; 2007).

In this research, a quadratic rotation-orthogonal composite experimental design, with three variables (at five levels each) and five response functions (drying time, average dehydration rate, WGC, MCWG, TA), and analysis method were employ to study the effect of the three variables on the individual response functions.

\section{MATERIALS AND METHODS}

\subsection{Wheat}

Wheat (Zhenong 1) harvested in June, 2004, from the experimental farm of Agronomy, Zhejiang University, was used for this experiment immediately after harvest. The initial moisture content was determined by drying five samples of wheat at $105{ }^{\circ} \mathrm{C}$ in a constant temperature oven till weight of the samples became constant (GB/5497-85, National Standard of China), and $25 \%$ (dry basis).

Before irradiation and drying experiments, samples were air-dried in natural condition to different initial moisture content respectively (Table 1). The sample mass for each drying test was $250 \mathrm{~g}$. Samples of wheat were stored in a refrigerator at $5{ }^{\circ} \mathrm{C}$ and warmed to room temperature before each tests.

Table 1. Quadratic rotation-orthogonal composite experimental design in coded and actual level of variables

\begin{tabular}{|c|c|c|c|c|c|c|}
\hline \multirow[b]{2}{*}{ Exp. No. } & \multicolumn{2}{|c|}{ Irradiation dosage } & \multicolumn{2}{|c|}{ Drying temperature } & \multicolumn{2}{|c|}{ Initial moisture content } \\
\hline & $\begin{array}{c}\text { Coded level } \\
x_{1}\end{array}$ & $\begin{array}{c}\text { Actual level } \\
X_{1}(\mathrm{kGy})\end{array}$ & Coded level $x_{2}$ & $\begin{array}{l}\text { Actual level } \\
X_{2}(\%, \text { d.b. })\end{array}$ & $\begin{array}{c}\text { Coded level } \\
x_{3}\end{array}$ & $\begin{array}{c}\text { Actual level } \\
X_{3}\left({ }^{\circ} \mathrm{C}\right)\end{array}$ \\
\hline 1 & 1 & 2.4 & 1 & 56 & 1 & 23.8 \\
\hline 2 & 1 & 2.4 & 1 & 56 & -1 & 20.2 \\
\hline 3 & 1 & 2.4 & -1 & 44 & 1 & 23.8 \\
\hline 4 & 1 & 2.4 & -1 & 44 & -1 & 20.2 \\
\hline 5 & -1 & 0.6 & 1 & 56 & 1 & 23.8 \\
\hline 6 & -1 & 0.6 & 1 & 56 & -1 & 20.2 \\
\hline 7 & -1 & 0.6 & -1 & 44 & 1 & 23.8 \\
\hline 8 & -1 & 0.6 & -1 & 44 & -1 & 20.2 \\
\hline 9 & 1.682 & 3 & 0 & 50 & 0 & 22 \\
\hline 10 & -1.682 & 0 & 0 & 50 & 0 & 22 \\
\hline 11 & 0 & 1.5 & 1.682 & 60 & 0 & 22 \\
\hline 12 & 0 & 1.5 & -1.682 & 40 & 0 & 22 \\
\hline 13 & 0 & 1.5 & 0 & 50 & 1.682 & 25 \\
\hline 14 & 0 & 1.5 & 0 & 50 & -1.682 & 19 \\
\hline $15^{*}$ & 0 & 1.5 & 0 & 50 & 0 & 22 \\
\hline
\end{tabular}

* Experiment 15 was repeated nine times. 


\subsection{Experimental procedure}

The wheat was irradiated by ${ }^{60} \mathrm{Co} \gamma$-ray in the Institute of Nuclearagriculture Sciences, Zhejiang University. The doses were controlled respectively (Table 1), and the dose rate was $1 \mathrm{kGy} / \mathrm{h}$.

Irradiated samples were symmetrically placed in a sifter. Drying experiments were conducted at the above different doses, air temperatures, and initial moisture contents (Table 1). Air velocity was kept at $0.5 \pm 0.1 \mathrm{~m} / \mathrm{s}$. The samples were dried until it reached a final moisture content of 14.5 $\pm 0.1 \%$ (dry base), which represented the safe moisture value for grain storage. All the drying tests were replicated three times.

The experimental setup consisted of a drying chamber. For each experiment, the setup was allowed to run with a dummy sample till the desired drying conditions attained steady state. The dummy sample container was then replaced quickly with the actual sample container. The sample container was periodically removed and was weighed to generate the moisture loss data on an electric-balance having a weighing capacity of 500 $\mathrm{g}$ with an accuracy $\pm 0.01 \mathrm{~g}$. While weighing the sample, a dummy sample container was placed in the drying chamber so as not to disturb the state drying conditions. Thus the moisture content at any stage during drying was determined once the initial moisture content was known, and the accuracy of moisture content was $\pm 0.1 \%$ based on the accuracy of electronic balance.

After drying experiment, wheat samples was milled into flour by milling with a Quadrumat Junior laboratory mill (Brabender OHG, Duisberg, Germany). After separating wheat bran, wheat flour extraction rate ranged from $70 \%$ to $80 \%$. The wheat flour samples were used for wet gluten content (WGC), moisture content of wet gluten (MCWG) and titratable acidity (TA).

\subsection{Response functions}

\subsubsection{Drying time}

Drying time was the total time for the samples drying from its initial moisture content to the same final moisture content $(14.5 \pm 0.02 \%$, drying base).

\subsubsection{Average dehydration rate}

Average dehydration rate was calculated with the value of initial moisture content (\%) minus final moisture content (\%) and divided by drying time (h). To increase the average dehydration rate was also one of the objectives of improving drying method. 
Gamma-Irradiation Pre-Treatment on the Drying Characteristics and Qualities of Wheat

\subsubsection{Gluten content}

Wet gluten yield were determined by the machine washing Method (GB/5506-85, National Standard of China). Paste was forming with $25.00 \pm 0.01 \mathrm{~g}$ flour $(\mathrm{W})$ mixed $12.5 \pm 0.1 \mathrm{~mL}$ of water, followed by washing for $10 \mathrm{~min}$ with water at a flow rate of $50-60 \mathrm{~mL} / \mathrm{min}$ on a special $88-\mu \mathrm{m}$ sieve using a Perten Glutomatic Gluten Index machine (Perten Instruments AB, S-141 05 Huddinge, Sweden) to wash away any remaining starch or coarse particles. Afterwards, the wet gluten piece was centrifuged at $6000 \mathrm{rpm}$ for $1 \mathrm{~min}$ on a special $600-\mu \mathrm{m}$ metallic sieve using a Perten Centrifuge 2015 machine (Perten Instruments AB, S-141 05 Huddinge, Sweden) and the wet gluten yield was obtained (W1). The wet gluten samples was cut into twelve pieces, placed in a tin and dried for $30 \mathrm{~min}$ at $155{ }^{\circ} \mathrm{C}$ using a special Perten Glutork 2020 dryer. After cooling in a desiccator, weight of dry gluten (W2) was recorded. The gluten indexes of wet gluten content (WGC) (Eq. 1), dry gluten content (DGC) (Eq. 2) and moisture content of wet gluten (MCWG) (Eq. 3) was obtained. Tests were carried out in triplicates for each sample.

$$
\begin{aligned}
& W G C=\frac{W_{1}}{W} \times 100 \% \\
& M C W G=\frac{W_{1}-W_{2}}{W_{2}} \times 100 \% \\
& D G C=\frac{W_{2}}{W} \times 100 \%
\end{aligned}
$$

\subsubsection{Titratable acidity}

The titratable acidity was expressed as sodium hydroxide required to neutralize the acids in a $100.00 \pm 0.01 \mathrm{~g}$ sample, using phenolphthalein as an indicator (AOAC, 1990) with the unit $\mathrm{mg} \mathrm{NaOH} / 100 \mathrm{~g}$. Triplicates were carried out for each sample.

\subsection{Experimental design and analysis of data}

The method employed was a three-variable (five levels of each variable), quadratic rotation-orthogonal composite experimental design with nine replications at the centre points $(0,0,0)$, in coded levels of variables $(-1.682$, $-1,0,1,1.682$ ) (Akhnazarova, et al., 1982). In three independent variables in 
controlling were: X1 (irradiation dosage), X2 (drying temperature), X3 (initial moisture content).

The experimental design in the actual (X) and coded (x) levels of variables was shown in Table 1 . The response function y, i.e., drying time, average dehydration rate, WGC, MCWG, TA was approximated by a second degree polynomial (Eq. 4) with linear, quadratic and interaction effects (in coded level of variables) using the method of least squares (Little, et al., 1978).

$$
y_{k}=b_{0}+\sum_{i=1}^{n} b_{i} x_{i}+\sum_{i=1}^{n} \sum_{\substack{j=1 \\ i \leq j}}^{n} b_{i j} x_{i} x_{j}
$$

The number of variables was denoted by $n$, and $i, j, k$ were integers. The coefficients of the polynomials were represented by b0, bi, bij; when $\mathrm{i}<\mathrm{j}$, bij represents the interaction effects of the variables xi and xj. Analysis of variance (ANOVA) was conducted using the SAS software (SAS, 1999). Response surface graphs were obtained from the regression equations in actual level of variables, keeping the response function on the $\mathrm{Z}$ axes with $\mathrm{X}$ and $\mathrm{Y}$ axes representing the two independent variables while keeping the other variable at its optimum point.

\section{RESULTS AND DISCUSSION}

The experimental results on the effect of the three variables (irradiation dosage, initial moisture content and drying temperature) on the five response functions or targeted parameters (drying time, average dehydration rate, WGC, MCWG, TA) were detected and the condensed analysis of variances (ANOVA, in coded level of variables) table was shown in Table 2 for all the five response functions. The coefficients of the second order polynomial (in actual level of variables) were cited in Table 3 for case in using them to predict the response functions. The response surfaces, with $\mathrm{X}$ and $\mathrm{Y}$ axes representing two of the most influential variables while keeping another variable constant at their centre point (Fig. 1-5) (other response surface graphs were omitted), were presented to aid in visualizing the effect of the variables.

\subsection{Drying time}

A high correlation coefficient $(\mathrm{r}=0.971, \mathrm{p} \leqslant 0.01)$ indicated the suitability of the second order polynomial to predict the drying time (Y1) (Table 2). Among the variables, total linear effect $(p \leqslant 0.01)$ dominated the total quadratic effect $(p \leqslant 0.01)$, and the total interaction effect $(p \leqslant 0.05)$. Similar 
those conclusions could be draw from the other functions except average dehydration rate. Of the individual variables, drying temperature had the maximum negative effect $(\mathrm{p} \leqslant 0.01)$ on drying time followed by the positive effect of initial moisture content $(p \leqslant 0.01)$ and the negative effect of irradiation dosage $(p \leqslant 0.01)$. On the contrary, the quadratic effect of drying temperature was significant $(\mathrm{p} \leqslant 0.01)$ having a positive effect. Among the various interactions, the effect of drying temperature $\times$ initial moisture content was marginally significant $(\mathrm{p} \leqslant 0.05)$, having negative effect.

Table 2. Experimental results for the response functions

\begin{tabular}{|c|c|c|c|c|c|c|c|c|c|c|}
\hline \multirow[b]{2}{*}{$\begin{array}{l}\text { Source of } \\
\text { variations }\end{array}$} & \multicolumn{2}{|c|}{$Y_{1}$} & \multicolumn{2}{|c|}{$Y_{2}$} & \multicolumn{2}{|c|}{$Y_{3}$} & \multicolumn{2}{|c|}{$Y_{4}$} & \multicolumn{2}{|c|}{$Y_{5}$} \\
\hline & $\begin{array}{c}\text { Coefficient } \\
\text { of } \\
\text { polynomial }\end{array}$ & F-Value & $\begin{array}{c}\text { Coefficient } \\
\text { of } \\
\text { polynomial }\end{array}$ & F-Value & $\begin{array}{c}\text { Coefficient } \\
\text { of } \\
\text { polynomial }\end{array}$ & F-Value & $\begin{array}{c}\text { Coefficient } \\
\text { of } \\
\text { polynomial }\end{array}$ & F-Value & $\begin{array}{c}\text { Coefficient } \\
\text { of } \\
\text { polynomial }\end{array}$ & F-Value \\
\hline Constant & 170.526 & - & 2.995 & - & 26.171 & - & 154.246 & - & 17.646 & - \\
\hline$x_{1}$ & -22.583 & $20.763 * * *$ & 0.361 & $27.4448^{* * *}$ & -1.526 & $169.391 * * *$ & -16.241 & $180.350 * * *$ & 1.470 & $575.925^{* * *}$ \\
\hline$x_{2}$ & -68.879 & $193.164 * * *$ & 1.097 & $253.361^{* * *}$ & 0.191 & $2.655^{\mathrm{NS}}$ & 2.787 & $5.312 * *$ & 0.233 & $14.491 * * *$ \\
\hline$x_{3}$ & 28.058 & $32.052 * * *$ & 0.257 & $13.906^{* * * *}$ & -0.328 & $7.834 * *$ & -3.946 & $10.646^{* * *}$ & 0.486 & $62.930^{* * *}$ \\
\hline$x_{1}^{2}$ & 1.122 & $0.050^{\mathrm{NS}}$ & 0.057 & $0.767^{\mathrm{NS}}$ & 0.163 & $2.039^{\mathrm{NS}}$ & 2.094 & $3.210^{*}$ & -0.096 & $2.577^{\mathrm{NS}}$ \\
\hline$x_{2}^{2}$ & 18.800 & $16.792 * * *$ & 0.098 & $2.306^{\mathrm{NS}}$ & 0.994 & $83.252 * * *$ & 10.173 & $81.852 * * *$ & -0.527 & $85.618^{* * *}$ \\
\hline$x_{3}^{2}$ & -5.065 & $1.282^{\mathrm{NS}}$ & 0.036 & $0.298^{\mathrm{NS}}$ & 0.181 & $2.534^{\mathrm{NS}}$ & 2.235 & 3.681 * & -0.103 & $2.995^{\mathrm{NS}}$ \\
\hline$x_{1} x_{2}$ & 8.125 & $1.575^{\mathrm{NS}}$ & 0.011 & $0.016^{\mathrm{NS}}$ & -0.025 & $0.027^{\mathrm{NS}}$ & -0.025 & $0.000^{\mathrm{NS}}$ & 0.000 & $0.000^{\mathrm{NS}}$ \\
\hline$x_{1} x_{3}$ & 4.375 & $0.457^{\mathrm{NS}}$ & -0.068 & $0.571^{\mathrm{NS}}$ & 0.025 & $0.027^{\mathrm{NS}}$ & 0.025 & $0.000^{\mathrm{NS}}$ & 0.003 & $0.001^{\mathrm{Ns}}$ \\
\hline$x_{2} x_{3}$ & -15.625 & $5.823^{* *}$ & 0.254 & 7.931 ** & 0.000 & $0.000^{\mathrm{NS}}$ & -0.025 & $0.000^{\mathrm{NS}}$ & 0.003 & $0.001^{\mathrm{NS}}$ \\
\hline TLE & - & $245.978^{* * *}$ & - & $294.711^{* * *}$ & - & $179.880^{* * *}$ & - & $196.308^{* * *}$ & - & $653.346^{* * *}$ \\
\hline TQE & - & $18.124^{* * *}$ & - & $3.370^{\mathrm{NS}}$ & - & $87.825^{* * *}$ & - & $88.743^{* * *}$ & - & $91.190^{\star * *}$ \\
\hline TIE & - & $7.854 * *$ & - & $8.518^{* *}$ & - & $0.054^{\mathrm{NS}}$ & - & $0.001^{\text {NS }}$ & - & $0.003^{\mathrm{NS}}$ \\
\hline$r$ & $0.971 \% * *$ & - & $0.963 * * *$ & - & $0.983 * * *$ & - & $0.978^{* * *}$ & - & $0.939 * * *$ & - \\
\hline
\end{tabular}

${ }^{a}$ Variables : $x_{1^{-}}$irradiation dosage, $x_{2^{-}}$drying temperature, $x_{3^{-}}$initial moisture content. TLE: total linear effect; TQE: total quadratic effect; TIE: total interaction effect;

NS: non-significant at $p>0.10$. *Significant at $p \leq 0.10$. ** Significant at $p \leq 0.05$. ***Significant at $p \leq 0.01$; Response functions: $Y_{1}=$ drying time, $Y_{2}=$ average dehydration rate, $Y_{3}=$ wet gluten content, $Y_{4}=$ moisture content of wet gluten, $Y_{5}=$ titratable acidity.

The response surface of effect of drying temperature and initial moisture content on drying time was shown in Fig. 1 based on the equation in Table 3. It could be found that drying time was reduced with the increasing drying temperature and decreasing initial moisture content. The effect of drying temperature was more significant than initial moisture content. 


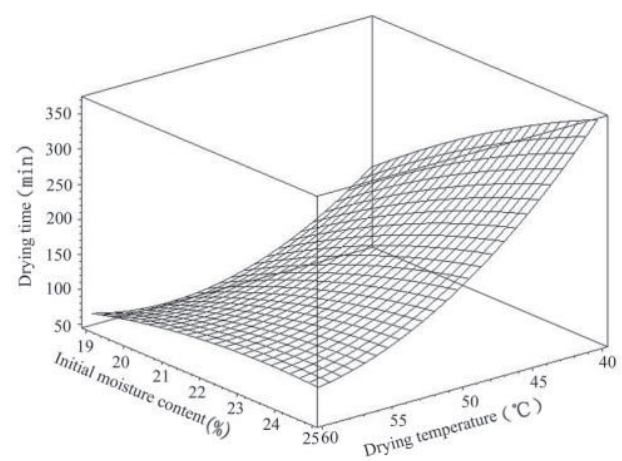

Fig. 1: Drying time as a function of drying temperature and initial moisture content (irradiation dosage at $1.5 \mathrm{kGy}$ )

Table 3. Regression equations for the response functions in the actual level of variables ${ }^{\mathrm{a}}$

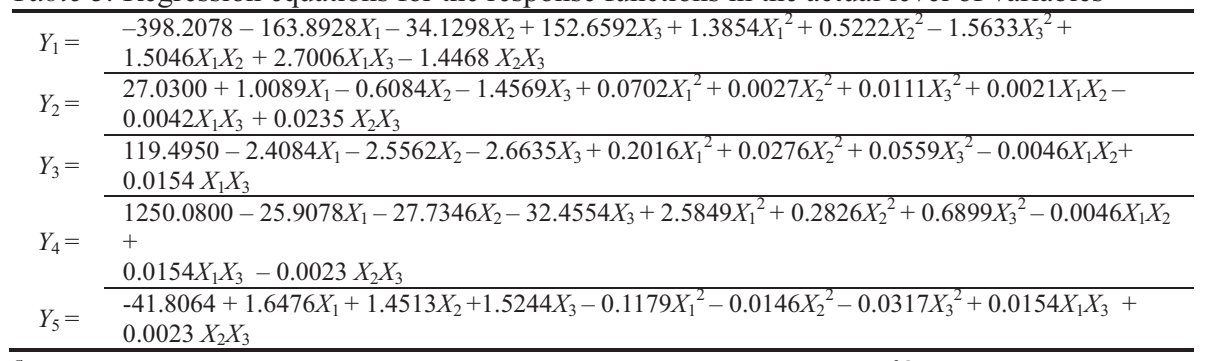

${ }^{a}$ Variables: $X_{1}=$ irradiation dosage $(k G y), X_{2}=$ drying temperature $\left({ }^{\circ} \mathrm{C}\right), X_{3}=$ initial moisture content (\%); Response functions: $Y_{1}=$ drying time (min), $Y_{2}=$ average dehydration rate $(\% / h), Y_{3}=$ wet gluten content $(\%), Y_{4}=$ moisture content of wet gluten $(\%), Y_{5}=$ titratable

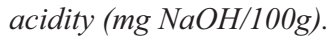

\subsection{Average dehydration rate}

The ANOVA table (Table 2) for average dehydration rate (Y2) showed a high correlation coefficient $(r=0.963, \mathrm{p} \leqslant 0.01)$ which indicates the suitability of the second order polynomial to predict average dehydration rate. Among the variables, total linear effect $(p \leqslant 0.01)$ dominated the total interaction effect $(p \leqslant 0.05)$, and the total quadratic effect $(p>0.1)$. Among the individual variables, drying temperature had the most positive effect $(\mathrm{p} \leqslant$ 0.01 ) on average dehydration rate followed by the positive effect of irradiation dosage $(p \leqslant 0.01)$ and the positive effect of initial moisture content $(p \leqslant 0.01)$. The quadratic effect of all the variables had no significant effect $(p>0.1)$ on average dehydration rate. Among their interactions, the effect of drying temperature $\times$ initial moisture content was marginally significant $(\mathrm{p} \leqslant 0.05)$, having positive effect. 
The response surface of effect of drying temperature and irradiation dosage on average dehydration rate was presented in Fig. 2 based on the equation in Table 3 . It was clearly that, as irradiation dosage and drying temperature increased, average dehydration rate was increased. The effect of drying temperature was more significant than irradiation dosage.

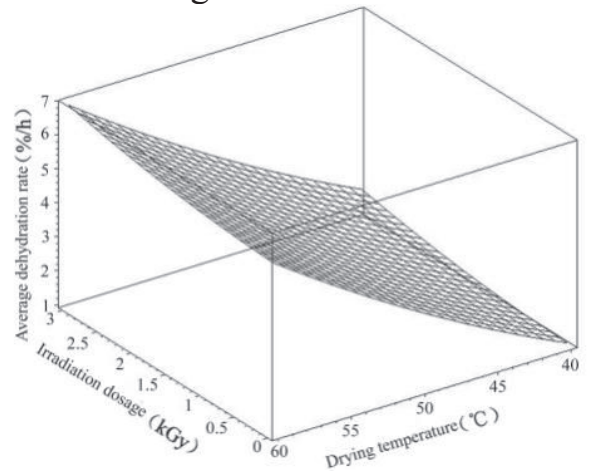

Fig. 2: Average dehydration rate as a function of drying temperature and irradiation dosage (initial moisture content at $22 \%$ )

\subsection{Wet gluten content (WGC)}

A high correlation coefficient $(\mathrm{r}=0.983, \mathrm{p} \leqslant 0.01)$ which indicates the suitability of the second order polynomial to predict wet gluten content (Y3) was shown by the ANOVA table (Table 2). All the various interactions had no significant effects $(\mathrm{p}>0.1)$ on wet gluten content. Irradiation dosage possessed the maximum influence (negative effect) $(p \leqslant 0.01)$ on wet gluten content followed by initial moisure content $(p \leqslant 0.05)$. The quadratic effect of drying temperature was significant $(\mathrm{p} \leqslant 0.01)$, having a positive effect and other quadratic effects had no significant effects $(\mathrm{p}>0.1)$.

The response surface of effect of irradiation dosage and initial moisture content on WGC was shown in Fig. 3 based on the equation in Table 3. It could be found that WGC was reduced with the increasing irradiation dosage and reduced followed by increased with the increasing initial moisture content. The effect of irradiation dosage was more significant than initial moisture content. 


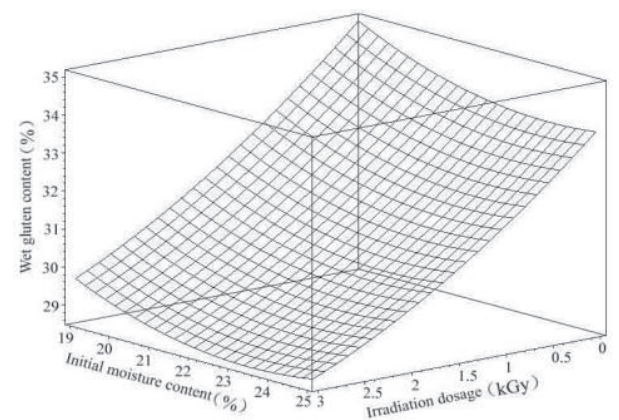

Fig. 3: Wet gluten content as a function of irradiation dosage and initial moisture content (drying temperature at $50{ }^{\circ} \mathrm{C}$ )

\subsection{Moisture content of wet gluten (MCWG)}

The ANOVA table (Table 2) showed a high correlation coefficient $(r=0.978, p \leqslant 0.01)$ which indicates the suitability of the second order polynomial to predict moisture content of wet gluten (Y4). Among the individual variables, irradiation dosage had the maximum negative effect $(\mathrm{p}$ $\leqslant 0.01)$ followed by the negative effect of initial moisture content $(\mathrm{p} \leqslant 0.01)$ and the positive effect of drying temperature $(p \leqslant 0.05)$ on MCWG. Among the quadratic effect of variables, drying temperature had the maximum positive effect $(\mathrm{p} \leqslant 0.01)$ followed by the positive effect of initial moisture content $(p \leqslant 0.10)$ and the positive effect of irradiation dosage $(p \leqslant 0.10)$ on MCWG. And all the various interactions had no significant effects $(p>0.1)$ on MCWG.

The response surface of effect of irradiation dosage and initial moisture content on MCWG was shown in Fig. 4 based on the equation in Table 3. It could be found that MCWG was decreased with the increasing irradiation dosage and decreased followed by increased with the increasing initial moisture content. The effect of irradiation dosage was more significant than initial moisture content.

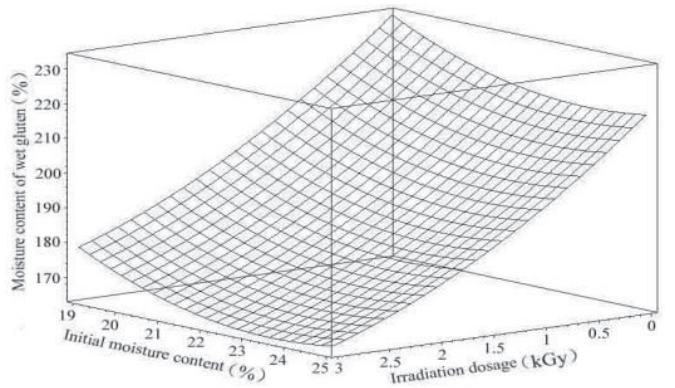

Fig. 4: Moisture content of wet gluten as a function of irradiation dosage and initial moisture content (drying temperature at $50{ }^{\circ} \mathrm{C}$ ) 


\subsection{Titratable acidity (TA)}

A high correlation coefficient $(r=0.971, p \leqslant 0.01)$ which indicates the suitability of the second order polynomial to predict titratable acidity (Y5) was shown by the ANOVA table (Table 2). Among the individual variables, irradiation dosage had the maximum positive effect $(p \leqslant 0.01)$ followed by the positive effect of initial moisture content $(p \leqslant 0.01)$ and the positive effect of drying temperature $(\mathrm{p} \leqslant 0.01)$ on TA. The quadratic effect of drying temperature had the maximum positive effect $(\mathrm{p} \leqslant 0.01)$ and other quadraic effects and all the various interactions had no significant effects $(p>0.1)$ on TA.

The response surface of effect of irradiation dosage and initial moisture content on TA was presented in Fig. 5 based on the equation in Table 3. It could be found that TA was increased with the increasing irradiation dosage and initial moisture content. The effect of irradiation dosage was more significant than drying temperature.

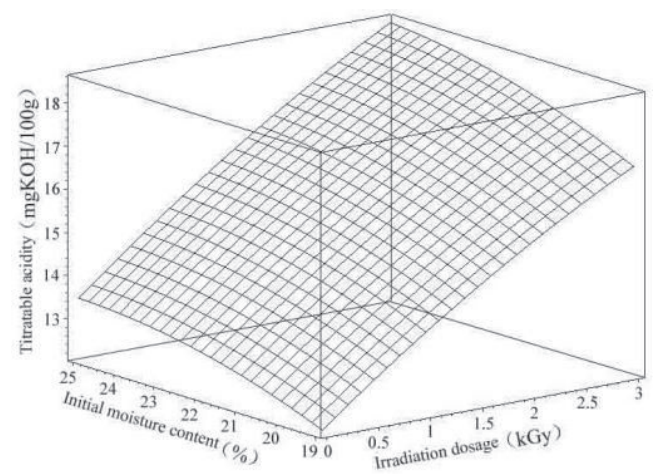

Fig. 5: titratable acidity as a function of irradiation dosage and initial moisture content (drying temperature at $50{ }^{\circ} \mathrm{C}$ )

\subsection{Effect of variables}

Among the variables, irradiation dosage had most significant linear effect on the five response functions (drying time, average dehydration rate, WGC, MCWG, TA) followed by initial moisture content and drying temperature. An increase in irradiation dosage had a negative effect on drying time and a positive effect on average dehydration rate. These effects improved drying characteristics, representing in shortening drying time and increasing average dehydration rate. It was assumably because of the damages and changes of tissue and structure of wheat grain caused by gamma irradiation 
(Yu, et al., 2006). An increase in irradiation dosage, had a negative effect on WGC and MCWG and a positive effect on TA. It was assumably because of the breakage or cleavage of long chains in amylopection caused by gamma irradiation (Wu et al., 2002).

\section{CONCLUSIONS}

The drying time, average dehydration rate, WGC, MCWG and TA were sensitive to irradiation dosage, drying temperature, and initial moisture content. Among the variables, drying temperature is most dominating factor on drying characteristics and irradiation dosage is most dominating factor on the quality of wheat flour.

Irradiation dosage had negative effect on drying time, WGC and MCWG, and positive effect on average dehydration rate and TA. Drying temperature had negative effect on drying time, and positive effect on average dehydration rate $\mathrm{WGC}, \mathrm{MCWG}$ and $\mathrm{TA}$. Initial moisture content had negative effect on WGC and MCWG, and positive effect on drying time, average dehydration rate and TA.

\section{ACKNOWLEDGEMENTS}

The authors acknowledge the financial support of Chinese National Foundation of Nature and Science through project 3047000, and the project was supported by China Postdoctoral Science Foundation 20060400320.

\section{REFERENCES}

Akhnazarova, S., Kafarov, V. Experiment optimization in chemistry and chemical engineering. Moscow: Mir. 1982, 151-240

Al-Kaisey, M.T., Mohammed, M.A., Alwan, A.H., Mohammed, M.H. The effect of gamma irradiation on the viscosity of two barley cultivars for broiler chicks. Radiation Physics and Chemistry, 2002, 63: 295-297

AOAC. Official method of analysis 14th ed.. Association of Official Analytical Chemists, Washington DC, USA. 1990

Bidawid, S., Farber, J. M., Sattar, S.A. Inactivation of hepatitis A virus (HAV) in fruits and vegetables by gamma irradiation. International Journal of Food Microbiology 2000, 57: 9197

Follett, P.A. Irradiation to control insects in fruits and vegetables for export from Hawaii. Radiation Physics and Chemistry, 2004, 71: 163-166

Formanek, Z., Lynch, A., Galvin, K., Farkas, J., Kerry, J.P. Combined effects of irradiation and the use of natural antioxidants on the shelf life stability of overwrapped minced beef. Meat Science, 2003, 63: 433-440 
Hallman, G.J. Irradiation disinfestation of apple maggot (Diptera : Tephritidae) in hypoxic and low temperature storage. Journal of economic entomology, 2004, 97: 1245-1248

Kamat, A., Pingulkar, K., Bhushan, B., Gholap, A., Thomas, P. Potential application of low dose gamma irradiation to improve the microbiological safety of fresh coriander leaves. Food Control, 2003, 14: 529-537

Little, T.M., Hills, F.J. Agricultural experimentation: design and analysis. New York: John Wiley, 1978, 247-266

Wang, J., Chao, Y. Drying characteristics of irradiated apple slices. Journal of Food Engineering, 2002. 52: 83-88

Wang, J., Chao, Y. Effect of gamma irradiation on quality of dried potato. Radiation Physics and Chemistry, 2003, 66: 293-297

Wu, D. X., Shu, Q.Y., Wang, Z.H., Xia, Y.W. Effect of gamma irradiation on starch viscosity and physicochemical properties of different rice. Radiation Physics and Chemistry, 2002, 65: 79-86

$\mathrm{Yu}$ Y, Wang J. Effect of gamma-ray irradiation on drying characteristics of wheat. Biosyst. Eng., 2006, 95:219-225

$\mathrm{Yu}$ Y, Wang J. Effect of $\gamma$ irradiation pre-treatment on drying characteristics and qualities of rice. Radiat. Phys. Chem., 2005, 74:378-383

$\mathrm{Yu} \mathrm{Y}$, Wang J. Effect of $\gamma$-irradiation treatment before drying on qualities of dried rice. J. Food Eng., 2007, 78:529-536 